\title{
Quantification of efficiency of beneficiation of lunar regolith
}

\author{
Steve Trigwell ${ }^{1}$, John Lane $^{2}$, James Captain ${ }^{3}$, Kyle Weis ${ }^{3}$, Jacqueline Quinn ${ }^{4}$, and Fumiya \\ Watanabe ${ }^{5}$ \\ ${ }^{I}$ Sierra Lobo, Kennedy Space Center, FL 32899 \\ ${ }^{2}$ EASi, Kennedy Space Center, FL 32899 \\ ${ }^{3}$ QinetiQ North America, Kennedy Space Center, FL 32899 \\ ${ }^{4}$ NASA, Kennedy Space Center, FL 32899 \\ ${ }^{5}$ Nanotechnology Center, University of Arkansas at Little Rock, \\ 2801 South University Avenue, Little Rock, AR, 72204
}

\begin{abstract}
Electrostatic beneficiation of lunar regolith is being researched at Kennedy Space Center to enhance the ilmenite concentration of the regolith for the production of oxygen in in-situ resource utilization on the lunar surface. Ilmenite enrichment of up to $200 \%$ was achieved using lunar simulants. For the most accurate quanitification of the regolith particles, standard petrographic methods are typically followed, but in order to optimize the process, many hundreds of samples were generated in this study that made the standard analysis methods time prohibitive. In the current studies, X-ray photoelectron spectroscopy (XPS) and Secondary Electron microscopy/Energy Dispersive Spectroscopy (SEM/EDS) were used that could automatically, and quickly, analyze many separated fractions of lunar simulant. In order to test the accuracy of the quantification, test mixture samples of known quantities of ilmenite $(2,5,10$, and $20 \mathrm{wt} \%$ ) in silica (pure quartz powder), were analyzed by XPS and EDS. The results showed that quantification for low concentrations of ilmenite in silica could be accurately achieved by both XPS and EDS, knowing the limitations of the techniques.
\end{abstract}




\section{Introduction}

Any future extraterrestrial base and habitat, whether on the moon or further afield on Mars, must have the ability to be self sustaining in such areas as oxygen, water, and construction materials to offset the considerable cost and energy in bringing it from earth. In other words, they must be able to live off the land. In-situ Resource Utilization (ISRU) has become the focus of intensive research at NASA Kennedy Space Center (KSC). Refinement or enrichment of specific minerals in the regolith into an industrial feedstock before it is chemically processed may be more desirable as it would reduce the size and energy requirements required to produce the virgin material and it may significantly reduce the process' complexity. The feasibility of extracting oxygen from the $\mathrm{FeO}$ component by hydrogen reduction in terrestrial soils has been demonstrated (Williams and Mullins, 1983), and a number of oxygen production technologies are being tested. Ilmenite is a mineral of interest on the moon as a source of iron, titanium, and oxygen $\left(\mathrm{FeTiO}_{3}\right)($ Heiken et al. 1993, Zhao and Shadman 1993), and therefore any method to increase its natural abundance in excavated ore before processing would be a considerable advantage.

Electrostatic beneficiation of lunar regolith is currently used to enhance the ilmenite concentration in lunar regolith and is being investigated as part of the ISRU program. In experiments at KSC, lunar simulant JSC-1A and actual lunar regolith from the Apollo 14 mission have been tested. The regolith is tribocharged by passing through a static mixer and allowed to fall through a high electric field produced by a pair of high voltage parallel plates, and into a series of seven collection bins to collect the separated regolith as shown in Figures 1 and 2, as previously described in Trigwell et al., 2009, and Captain et al. 2007. The principle is that the different minerals within the regolith will tribocharge differently depending upon the work 
function difference between the specific mineral and the material of the static charger (Sternovsky et al. 2002, Trigwell et al. 2009).

The lunar regolith grains and the lunar environment are ideal for triboelectrification and electrostatic separation, with the lack of moisture preventing the grains from sticking together, lack of atmospheric gaseous breakdown allowing higher voltages to be used on the separation plates, and the gravity only being $1 / 6$ that of earth that will allow the particles longer charge contact times and time between the plates to enhance the separation.

The efficiency of the system then depends upon accurate analysis of the separated fractions to quantify the mineral compositions for enrichment. In this study, regolith lots were sieved into several size fractions to determine efficiency of beneficiation as a function of particle size, and mixtures of various compositions of feldspar, olivine, pyroxene, and ilmenite as control samples were also sampled as a method to test the efficiency of separation. This resulted in a matrix of several hundred samples requiring analysis. The samples were analyzed by X-ray photoelectron spectroscopy (XPS) and Secondary Electron microscopy/Energy Dispersive Spectroscopy (SEM/EDS). These techniques allowed for reasonably quick turnaround of multiple sample lots. In the development and optimization of an electrostatic separator for ISRU beneficiation, a pathological problem has been the unknown errors associated with element percentages from spectroscopy data. Since the mineral of interest on the moon, ilmenite, starts out in concentrations varying from $0.4-12.8$ vol \%, depending upon the site on the moon (Heiken et al 1993), any increase or decrease in concentration as a result of electrostatic separation can easily be buried below the noise floor and reliable resolution of the analysis. This of course leads to confusion in interpreting the results of any attempt to improve and optimize the electrostatic separator hardware configuration. In this paper, the data obtained by XPS and SEM/EDS on 
carefully prepared mixtures of silica and ilmenite was compared and analyzed for accuracy as a viable method for analyzing and quantifying beneficiated lunar regolith. The ilmenite control was also characterized by X-ray Diffraction (XRD) to determine the exact nature of the composition to assist in interpreting the XPS and SEM/EDS data. The results showed that by utilizing standards, reasonable and accurate data was obtained.

\section{A Concentration matrix for evaluating XPS and EDS analysis efficiency}

The inherent scatter in elemental percentages (by atomic number $\mathrm{At} \%$, or atomic weight $\mathrm{Wt} \%$ ) reported by electron spectroscopy analysis often severely undermines the resolution needed to detect the important features under investigation. This section describes a simple $M \times N$ matrix involving sample preparation that enables the micro-analysist to peer below this typically high noise floor of element percentages reported by the spectroscopy analysis, thus yielding more meaningful data.

Mixed concentrations of ilmenite powder $\left(\mathrm{FeTiO}_{3}\right)($ Reade Advanced Materials, $\mathrm{RI})$ and fused pure silica $\left(\mathrm{SiO}_{2}\right)(\mathrm{PEMCO}, \mathrm{Inc}, \mathrm{NY})$ were made up. In this case, there are $M=4$ concentration levels of the original mix under test: $2 \%$ ilmenite (98\% silca); $5 \%$ ilmenite ( $95 \%$ silica); $10 \%$ ilmenite ( $90 \%$ silca); and $20 \%$ ilmenite ( $80 \%$ silica). Table 1 shows the initial percentages of ilmenite and silica by weight in the four test mixtures. In order to compare this to SEM/EDS and XPS analysis, the values in Table 1 must first be converted to atomic percentage At $\%$ or weight percentage $\mathrm{Wt} \%$. One approach is to define a relative weight (or molar mass) for each component mineral based on the atomic weights of each constituent element:

$$
\begin{array}{cc}
w_{x}=w_{T i}+w_{F e}+3 w_{O} & \text { for ilmenite } \\
w_{b}=w_{S i}+2 w_{O} & \text { for silica }
\end{array}
$$

where $w_{T i}=47.90, w_{F e}=55.85, w_{S i}=28.09$, and $w_{O}=16.00$ are the atomic weights. 
The atomic number percent At $\%$ for each element in the mix is calculated by first expressing the mass of each of the component minerals in Table 1 in terms of the absolute atomic weights:

$$
\begin{array}{ll}
m_{x}=n_{x} w_{x} & \text { for ilmenite } \\
m_{b}=n_{b} w_{b} & \text { for silica }
\end{array}
$$

where $n_{x}$ is the number of ilmenite molecules in the sample and $n_{b}$ is the number of molecules in the silica background. The fraction of atoms of each element in the mixture is just the ratio of the number of atoms of that element divided by the total numbers of atoms in the sample:

$$
\begin{array}{ll}
\alpha_{T i}=\frac{n_{x}}{5 n_{x}+3 n_{b}}=\frac{1}{5+3 x} & \text { for titanium } \\
\alpha_{F e}=\frac{n_{x}}{5 n_{x}+3 n_{b}}=\frac{1}{5+3 x} & \text { for iron } \\
\alpha_{S i}=\frac{n_{b}}{5 n_{x}+3 n_{b}}=\frac{x}{5+3 x} & \text { for silicon } \\
\alpha_{O}=\frac{3 n_{x}+2 n_{b}}{5 n_{x}+3 n_{b}}=\frac{3+2 x}{5+3 x} & \text { for oxygen }
\end{array}
$$

where $x \equiv n_{b} / n_{x}$. The percentage $p$ from Table 1 can be expressed in terms of $x$ and Equations (2):

$$
\begin{gathered}
p=\frac{n_{x} w_{x}}{n_{x} w_{x}+n_{b} w_{b}}=\frac{w_{x}}{w_{x}+w_{b} x} \\
x=\left(\frac{1-p}{p}\right) \frac{w_{x}}{w_{b}}
\end{gathered}
$$

The atomic number percentages from Equations (3) can now be expressed using the more useful quantity $p$ :

$$
\alpha_{T i}=\frac{w_{b} p}{5 w_{b} p+3 w_{x}(1-p)} \quad \text { for titanium }
$$




$$
\begin{array}{ll}
\alpha_{F e}=\frac{w_{b} p}{5 w_{b} p+3 w_{x}(1-p)} & \text { for iron } \\
\alpha_{S i}=\frac{w_{x}(1-p)}{5 w_{b} p+3 w_{x}(1-p)} & \text { for silicon } \\
\alpha_{O}=\frac{3 w_{b} p+2 w_{x}(1-p)}{5 w_{b} p+3 w_{x}(1-p)} & \text { for oxygen }
\end{array}
$$

Table 2 contains the final atomic percentages for each of the four elements using the mixture percentages from Table 1, the atomic number percent calculations of Equations (5) and atomic weights from Equations (1).

\section{Experimental}

In order to get an understanding of the variation in XPS and SEM/EDS elemental analysis data, several analysis regions on the same sample, as well as regions on different samples of the same material, were compared.

A JEOL-7500F scanning electron microscope (SEM) with an electron dispersive X-ray spectrometer (EDS) was used to take images and perform elemental analysis of regolith particles. The SEM field of view (FOV) was set to approximately 400 to $1000 \mu \mathrm{m}$ in order to attempt correlation with the XPS spectrum. The instrument is equipped with a Thermo NORAN System Six Energy Dispersive x-ray Spectroscopy (EDS) system for elemental analysis. Electron beam energies were 1-2 $\mathrm{kV}$ during image and $15 \mathrm{kV}$ during EDS analysis. The sample chamber was held at a pressure of $9.6 \times 10^{-5} \mathrm{mbar}$ during imaging and analysis.

Figure 3 shows a typical EDS spectrum taken on lunar simulant where the characteristic peaks of the compositional elements are distinct. The elemental compositions were determined from the relative peak heights compared with known standards. For these analyses, the acceleration voltage used was $5 \mathrm{kV}$. The EDS X-ray signal originates from about $1 \mu \mathrm{m}$ into the sample, and so 
EDS gives information from more of the bulk of the particle. An SEM image of lunar simulant is shown in Figure 4(a), whereas in Figures 4(b) and (c) show the EDS map of Fe and Ti, respectively, showing the distribution of ilmenite particles in the test regolith mixture. The sample corresponds to one of the 5\% SEM/EDS test samples denoted by KSC-5a.

The XPS data were obtained on a Thermo Scientific K-Alpha X-ray photoelectron spectrometer at a background pressure of $1 \times 10^{-9}$ torr, using a monochromated $\mathrm{Al} \mathrm{K \alpha}(\mathrm{hv}=1436.6 \mathrm{eV}) \mathrm{x}-\mathrm{ray}$ source. The x-ray beam used was $100 \mathrm{~W}, 400 \mu \mathrm{m}$ in diameter. The collected data were referenced to the $\mathrm{C} 1 \mathrm{~s}$ peak to $284.6 \mathrm{eV}$.

Figure 5 shows a typical XPS spectrum taken from Apollo 14 regolith showing the detected elements. The quantification is determined by measuring the areas under the peaks and normalizing using sensitivity factors supplied by the instrument manufacturer. For XPS, the acquired spectrum is dependent upon the escape depth of the ejected photoelectrons, which is typically $50-100 \AA$, and hence XPS is more surface sensitive and gives information from the surface of the particle.

X-ray diffraction (XRD) spectrum was collected by Brukert ${ }^{\circledR}$ Discover D-8 XRD system equipped with a two dimensional detector and a $\mathrm{Cu}$ source $(0.154 \mathrm{~nm})$ utilizing theta-theta scan mode. After the background subtraction, the spectrum was analyzed against the ICDD database.

\section{Results and Discussion}

Figures 6 and 7 show an example of an $M \times N$ sample set using known pre-mixed concentrations of laboratory grade ilmenite powder $\left(\mathrm{FeTiO}_{3}\right)$ and silica $\left(\mathrm{SiO}_{2}\right)$. In this case, there are $M=4$ concentration levels of the original mix under test: $2 \%$ ilmenite ( $98 \%$ silca); $5 \%$ ilmenite $(95 \%$ silica); $10 \%$ ilmenite ( $90 \%$ silca); and $20 \%$ ilmenite ( $80 \%$ silica). For each of these $M$ sample groups, $N=10$ separate XPS samples were drawn. For SEM/EDS analysis, fewer samples were 
used, primarily because the SEM sample holder allowed for only six separate samples at a time, while the XPS sample holder contained 40 sample cavities. The value of $N$ varied from three to five in the SEM case, depending on the data scatter, which was lower at higher concentrations. By plotting the linear trend of the $M$ sample's known concentration versus the average of the $N$ samples, a much higher resolution of elemental analysis can be performed. The resulting trend also shows how the noise is affecting the data and at what point (in concentration) is it impractical to try to extract any further meaningful data.

Figures 6 and 7 show the results of the atomic percent measured by SEM/EDS and XPS on the $M$ $=4$ mixture samples listed in Table 1, where the horizontal axis is the calculated percentages from Table 2. Note that the values in Table 2 are ideal and assume a perfect chemical species of both ilmenite and silica. However, it is known that ilmenite degrades over time and transforms into other related minerals with different chemical ratios of elements. Figures 6 and 7 also show the average spectroscopy measured value and its linear regression. The constant in the linear regression formula is an approximation the spectroscopy measurement limit of each of the elements of interest. The linear regression plots show the extrapolation to the minimum concentration that could be detected by these techniques. In Figure 6, the Ti SEM curve reaches a theoretical minimum approximately at $0.17 \mathrm{At} \%$, while for the Ti XPS curve, at approximately $0.05 \mathrm{At} \%$. In Figure 7, the values are lower for Fe. Figure 8 displays the result of a regolith test matrix composed of JSC-1A simulant background and an ilmenite sample mixture. This $\mathrm{M} \mathrm{x} \mathrm{N}$ matrix ( $\mathrm{M}=5$ and $\mathrm{N} \sim 100)$ of SEM/EDS samples is plotted for the titanium results as a function of weight \% (as opposed to atomic \% in Figures 6 and 7). The same linear trend of averages is seen in this data set as in the previous KSC-nna set with the theoretical minimum Ti able to be detected at $1 \mathrm{Wt} \%$. The offset from the ideal linear correlation is similar to the offset seen in the 
XPS and SEM-Fe data of Figure 6 and 7. The observations from Figures 6 and 7 is that the Fe atomic concentrations obtained from the spectroscopy measurements were consistently lower than that of the calculated stoichiometry for the ilmenite shown in Table 2. Table 3 shows the XPS data summary performed on six samples of the ilmenite as received from Reade.

Considering that the composition of ilmenite is given as $\mathrm{FeTiO}_{3}$, it was expected that the XPS data would give the Fe:Ti ratio as 1:1, however, it was observed that the XPS data gives the ilmenite an Fe:Ti ratio of 1:1.8, as shown in Table 4. XRD analysis performed on the Reade ilmenite, showed peaks consistent with pseudorutile and rutile as well as ilmenite, the stoichiometries of which are also shown in Table 4 . From Table 4 it can be observed that the stoichiometry of pseudorutile plus rutile is close to that of the ilmenite measured by XPS. Suresh Babu et al (1994) and Premaratne and Rowson (2003) have shown that terrestrial ilmenite undergoes alteration over time to pseudorutile and eventually rutile/anatase. The degree of alteration depends upon weathering and time with incomplete alteration leading to the coexistence of ilmenite, pseudorutile and rutile ((Suresh Babu et al, 1994), which is evident in the XRD data and supported by the XPS data.

\section{Conclusions}

Mixtures of $2 \%$ ilmenite (98\% silca); $5 \%$ ilmenite ( $95 \%$ silica); $10 \%$ ilmenite (90\% silca); and $20 \%$ ilmenite ( $80 \%$ silica) were made up and analyzed by SEM/EDS and XPS. The data collected showed that reproducible and accurate data was obtained for quantification purposes for electrostatic beneficiation of lunar regolith. The minimum concentration of ilmenite that could be reliably quantified was $2 \mathrm{wt} \%$ ilmenite in silica and so these methods would not be suitable for lunar regolith where the ilmenite concentration after beneficiation was below 2 wt $\%$. 
The data also showed that terrestrial ilmenite is altered to form a combination of ilmenite, pseudorutile, and rutile which leads to an offset in the data. However, knowing this allowed for correct interpretation of the data. The ilmenite on the moon will not have this problem due to no weathering problems, however this may lead to incorrect optimization of the separator in terrestrial conditions. Work on the project is on-going utilizing lunar simulants and pristine lunar Apollo 14 regolith in vacuum.

\section{Acknowledgements}

This work was performed with initial funding from the NASA Kennedy Space Center's Center Director's Discretionary Fund (CDDF).

\section{References}

Captain, J.G., S. Trigwell, E.E. Arens, A.S. Biris, J.E. Captain, J.W. Quinn, and C.I. Calle. 2007. Tribocharging lunar simulant in vacuum for electrostatic beneficiation. AIP Conference Proceedings. STAIF 2007, Albuquerque, NM, pp. 951-956.

Eagle Engineering. 1988. Conceptual design of a lunar oxygen pilot plant lunar base systems study (LBSS) Task 4.2, EEI Report No. 88-182, NASA Johnson Space Center.

Heiken, G.H., D.T. Vaniman, and B.M. French, (Eds.). 1993. Lunar Source Book: A user's guide to the moon, UK: Cambridge University Press.

Premaratne, W.A.P.J., and Rowson, N.A. 2003. The processing of beach sand from Sri Lanka for the recovery of titanium using magnetic separation. Physical Separation in Science and Engineering, 12(1): 13-22.

Sternovsky, Z., A. Sickafoose, J. Colwell, S. Robertson, and M. Horanyi. 2002. Contact charging of lunar and martian dust stimulants. Journal of Geophysical Research, 107: 5105-5112, 
Suresh Babu, D.S., Thomas, K.A., Mohan Das, P.N., and Damodaran, A.D. 1994. Alteration of ilmenite in the Manavalakurichi deposit, India. Clays and Clay Minerals, 42(5): 567-571.

Trigwell S., J.G. Captain, E.E. Arens, J.W. Quinn, and C.I. Calle. 2009. The use of tribocharging in the electrostatic beneficiation of lunar stimulant. IEEE Trans. on Industry Apps., 45(3): 10601067.

Williams R.J. \& O. Mullins. 1983. Enhanced production of water from ilmenite, Lunar and Planetary Science XIV, Houston, TX.

Zhao, Y., and F. Shadman. 1993. Production of oxygen from lunar ilmenite. In Resources of Near Earth Space, ed. By J. Lewis, M.S. Mathews, and M.L. Guerrier, University of Arizona Press. pp. 149-178. 


\section{Figure captions}

Figure 1. Photograph of the electrostatic separator showing the feeder, static charger, separator plates, and collection bins.

Figure 2. Schematic of the principle of separation.

Figure 3. Sample EDX spectrum taken on lunar simulant

Figure 4. (a) SEM image of lunar regolith. (b) EDS map of Fe, and (c) EDS map of Ti showing presence of ilmenite mineral particles.

Figure 5. Sample XPS spectrum of Apollo 14 lunar regolith.

Figure 6. Results for titanium of a $M \times N$ sample set with $M=4$ concentration levels of the original mix under test: $2 \%$ ilmenite (98\% silca); $5 \%$ ilmenite (95\% silica); $10 \%$ ilmenite (90\% silca); and $20 \%$ ilmenite ( $80 \%$ silica). For each of these $M$ sample sets, $N=10$ XPS samples were drawn $(3 \leq N \leq 5$ for $\mathrm{SEM})$.

Figure 7. Results for iron of a $M \times N$ sample set with $M=4$ concentration levels of the original mix under test: $2 \%$ ilmenite (98\% silca); $5 \%$ ilmenite (95\% silica); $10 \%$ ilmenite (90\% silca); and $20 \%$ ilmenite ( $80 \%$ silica). For each of these $M$ sample sets, $N=10$ XPS samples were drawn $(3 \leq N \leq 5$ for SEM).

Figure 8. Result of a regolith test This $M x N$ matrix $(M=5$ and $N \sim 100)$ matrix composed of JSC-1A simulant background and an ilmenite sample mixture. 


\section{Table captions}

Table 1. Percent fraction of ilmenite and silica by weight in the four test mixtures.

Table 2. Atomic number percentages of each element in each test mixture.

Table 3. XPS data for Reade ilmenite (mean of 6 samples)

Table 4. Stoichiometry of minerals 


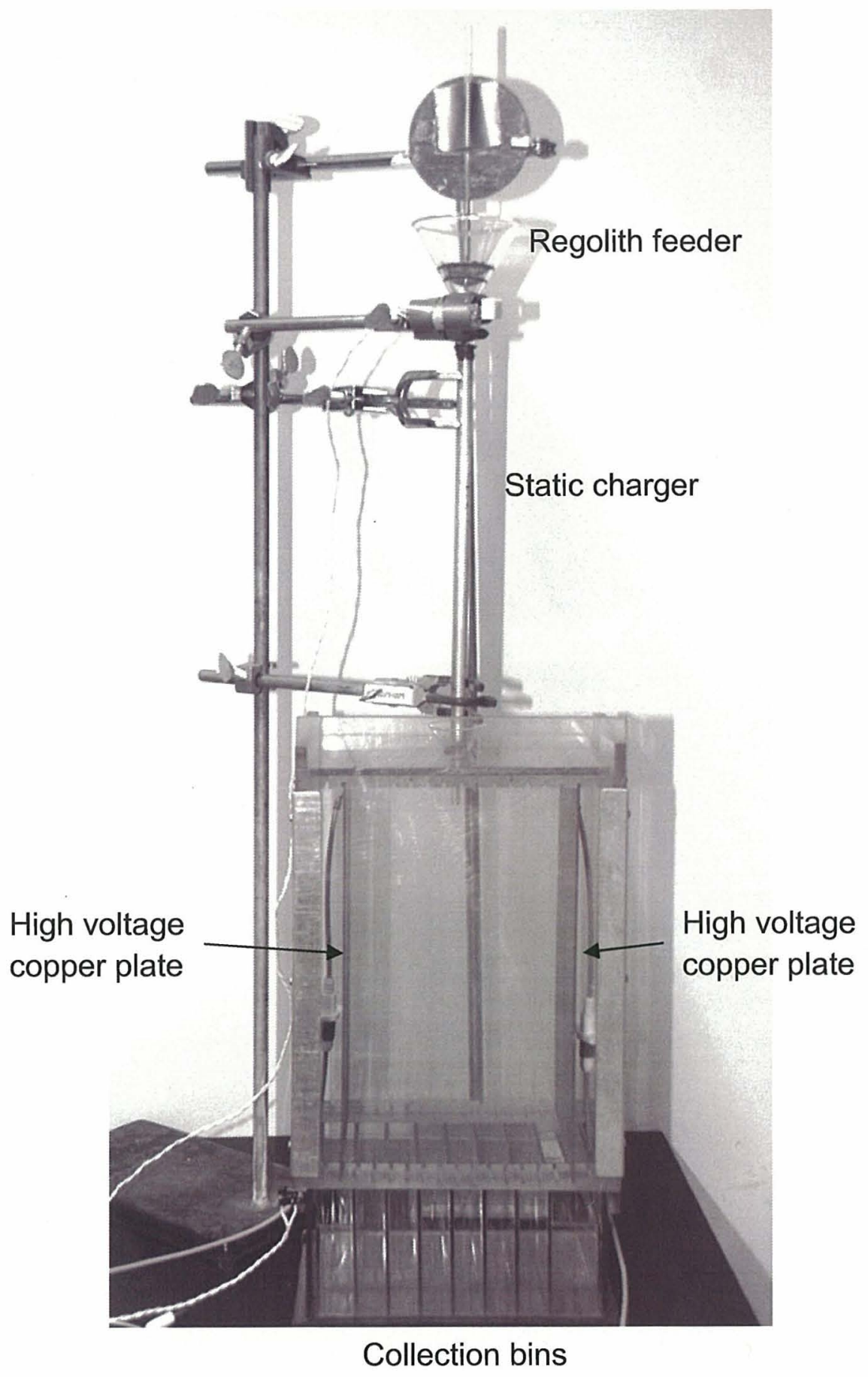

Fig 1. 


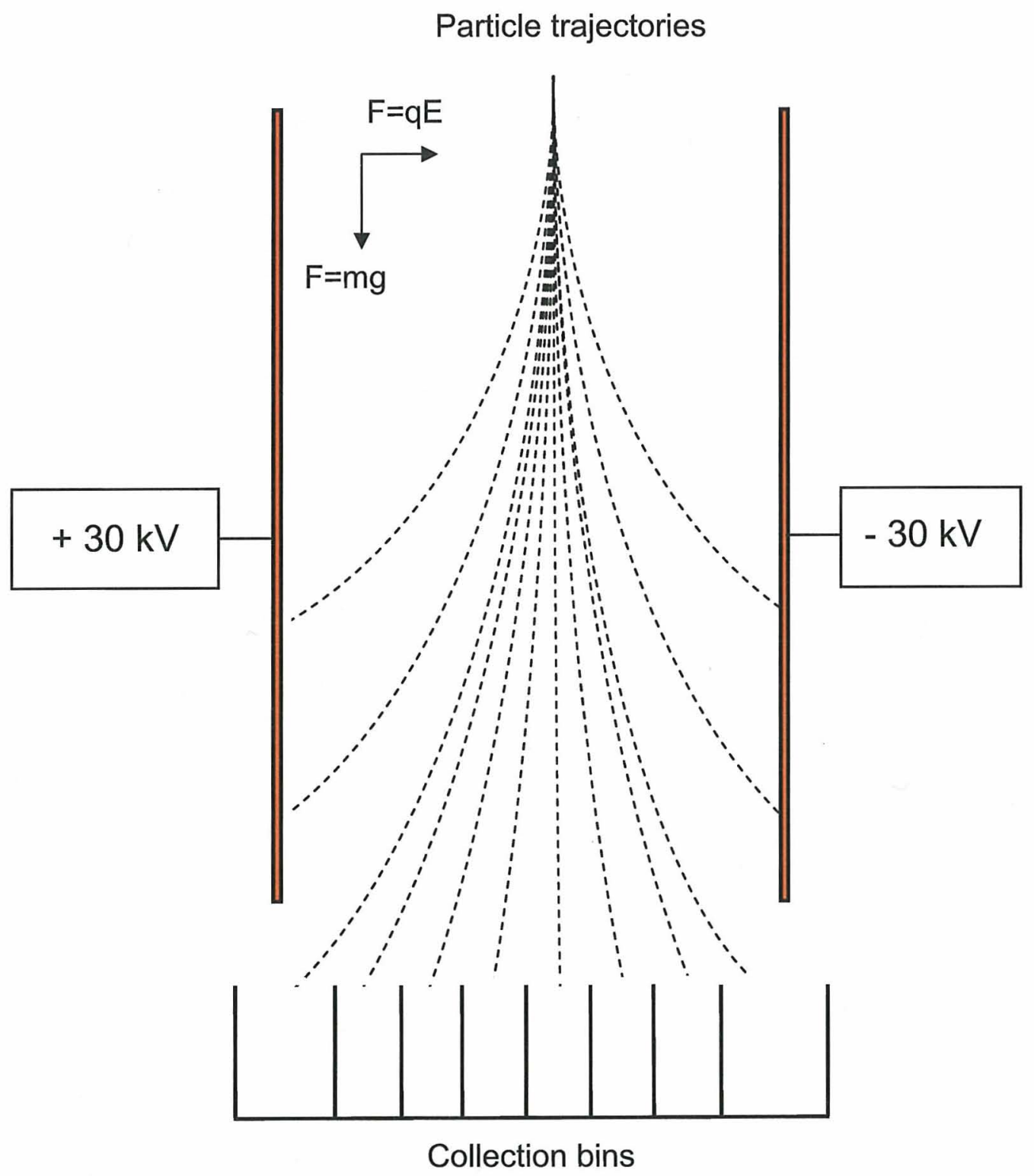

Fig. 2 




Fig. 3 


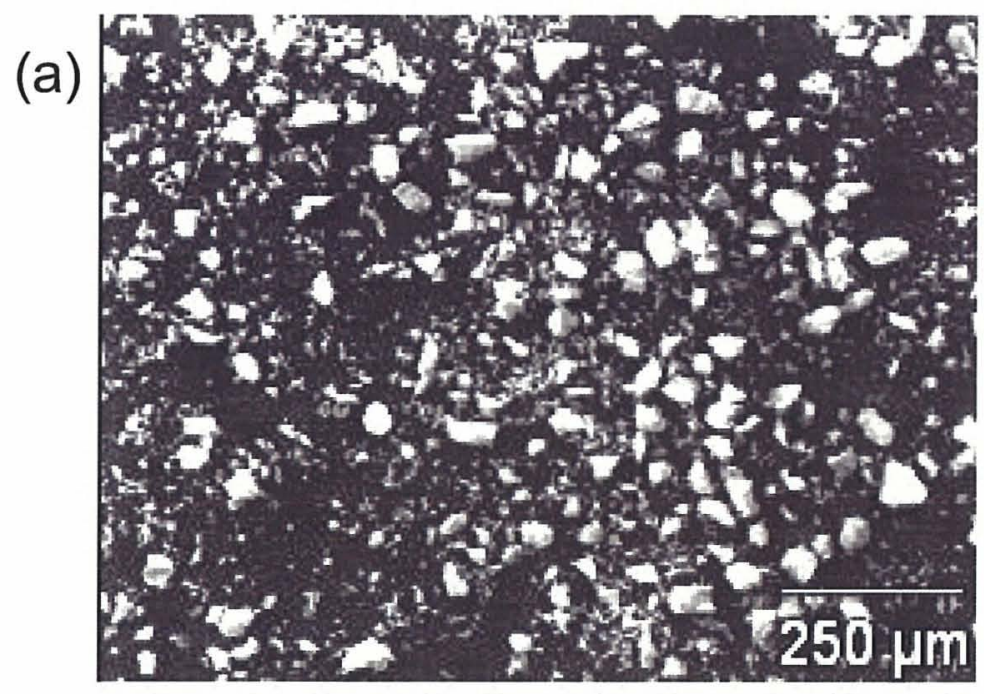

(b)

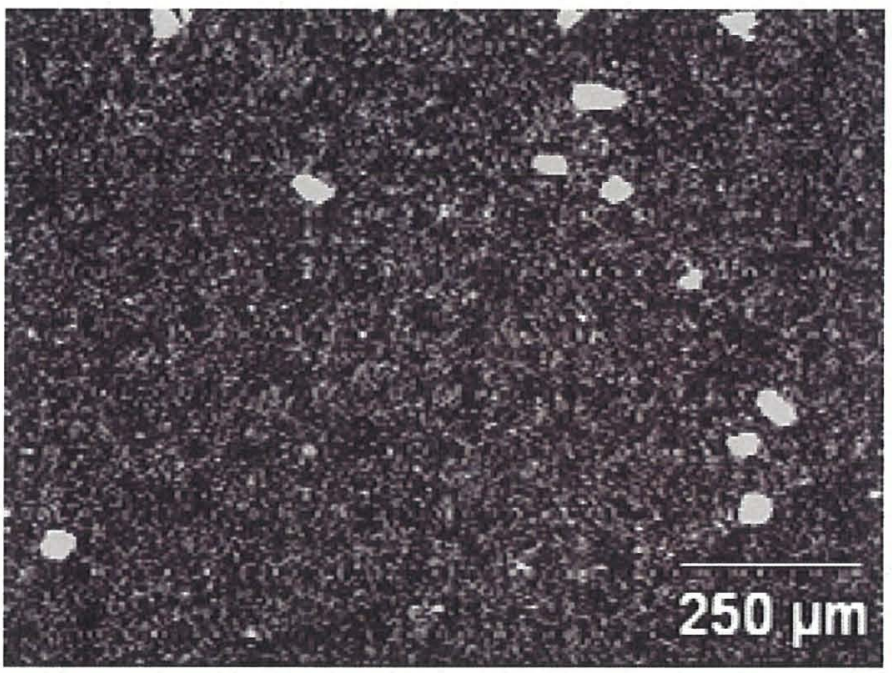

(c)

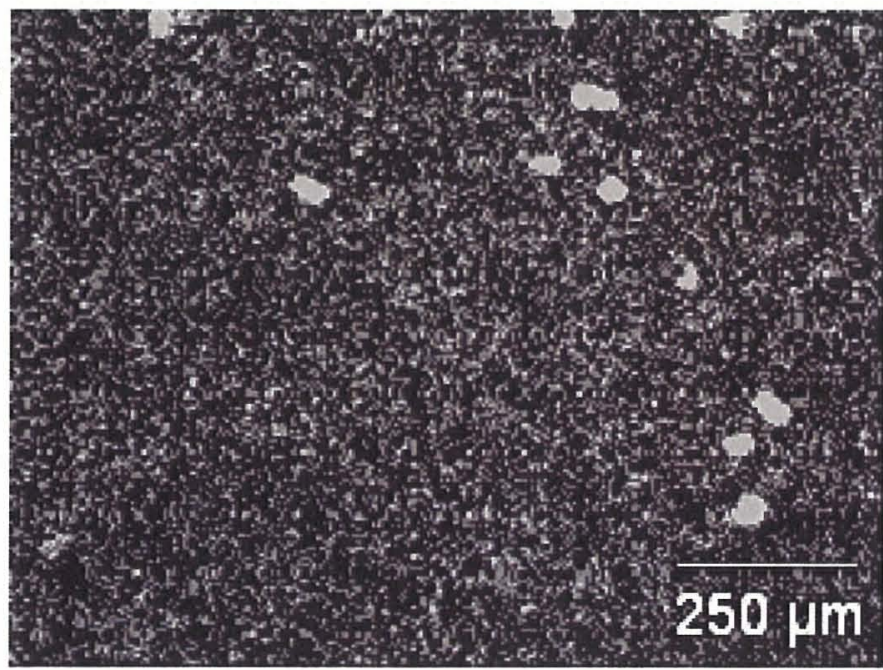

Fig. 4 


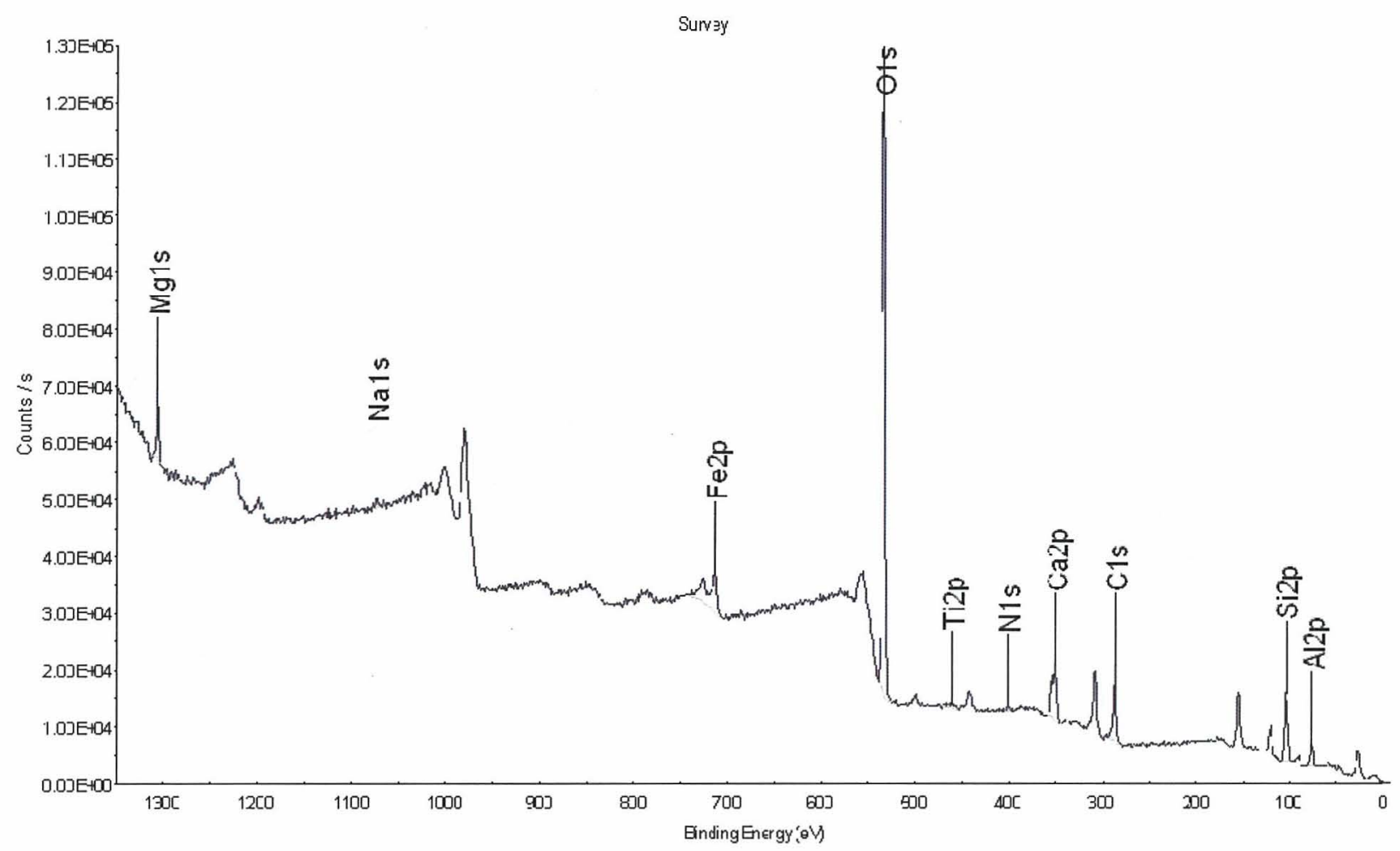

Fig. 5 


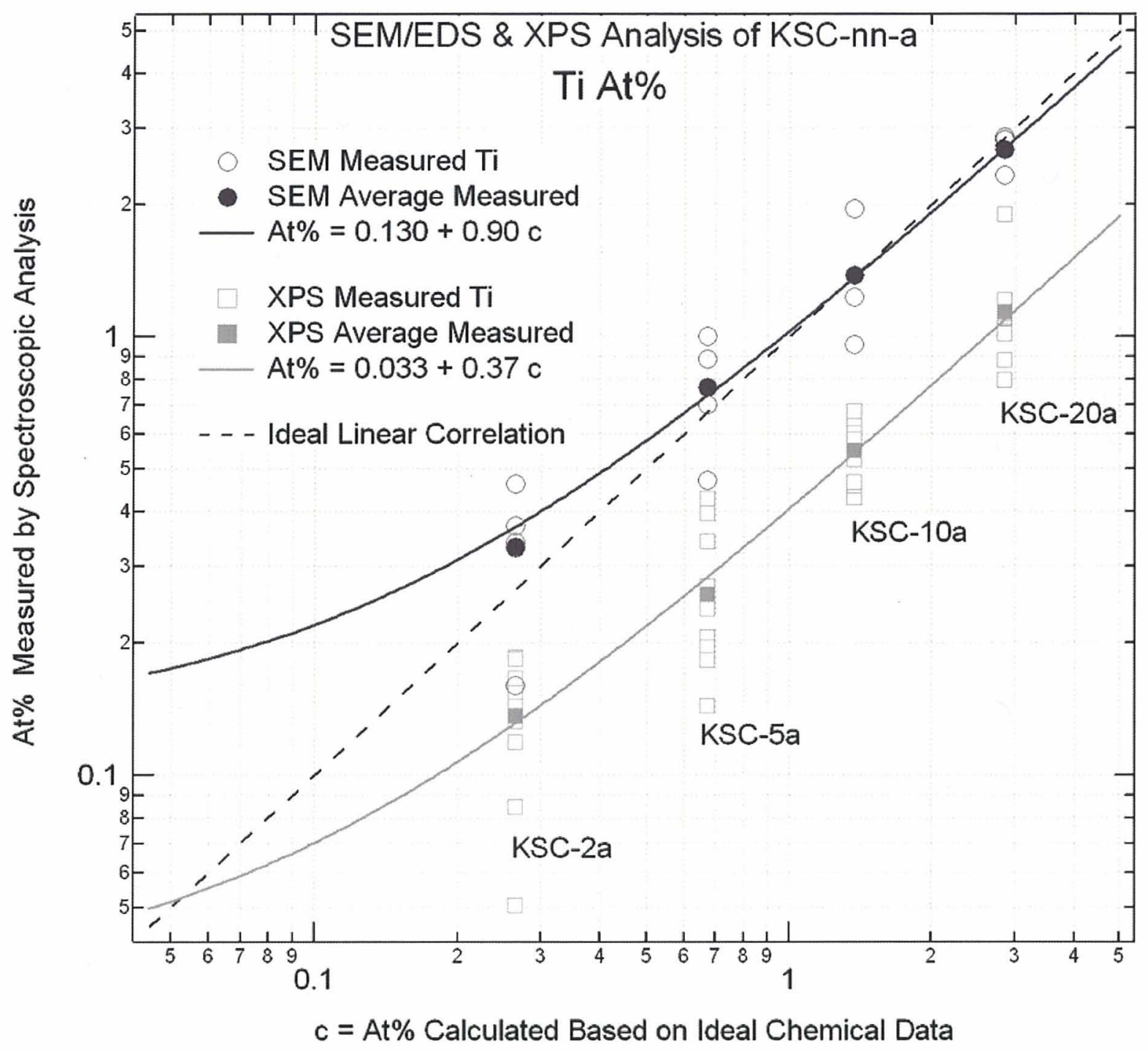

Fig. 6 


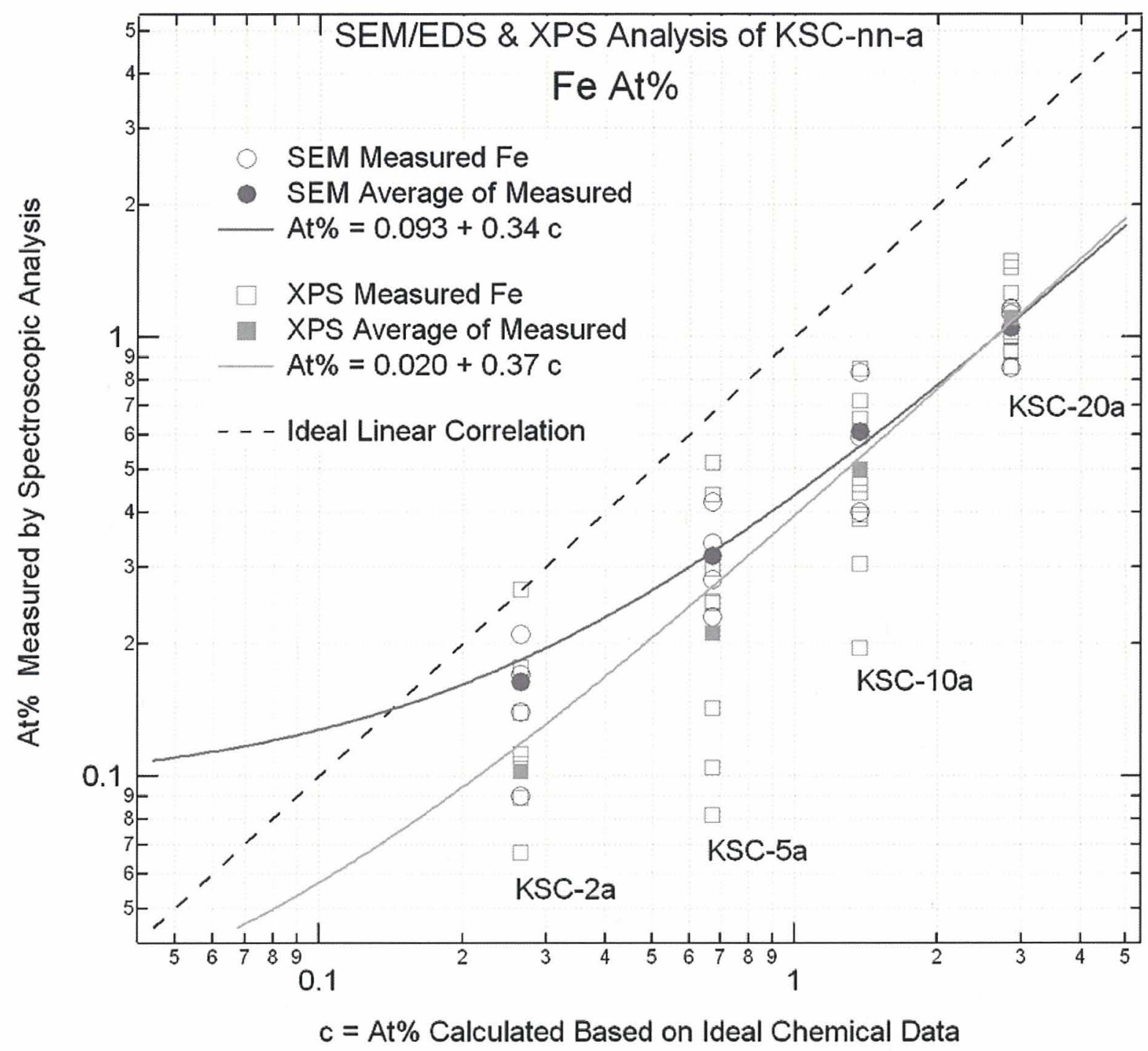

Fig. 7 




Fig. 8 
Table 1. Percent fraction of ilmenite and silica by weight in the four test mixtures.

\begin{tabular}{c|c|c|c}
\hline $\begin{array}{c}\text { Sample } \\
\text { Number }\end{array}$ & $m_{b}[\mathrm{~g}]-\mathrm{SiO}_{2}$ & $m_{x}[\mathrm{~g}]-\mathrm{FeTiO}_{3}$ & $p=\frac{m_{x}}{m_{x}+m_{b}}$ \\
\hline KSC-2a & 35.4273 & 0.7204 & 0.01993 \\
KSC-5a & 35.4949 & 1.8712 & 0.05008 \\
KSC-10a & 35.4770 & 3.9412 & 0.09998 \\
KSC-20a & 34.2615 & 8.5886 & 0.2004 \\
\hline
\end{tabular}


Table 2. Atomic number percentages of each element in each test mixture.

\begin{tabular}{c|c|c|c|c}
\hline $\begin{array}{c}\text { Sample } \\
\text { Number }\end{array}$ & At\%-Ti & At $\%-F e$ & At $\%-S i$ & At $\%-O$ \\
\hline KSC-2a & 0.265 & 0.265 & 32.892 & 66.578 \\
KSC-5a & 0.672 & 0.672 & 32.213 & 66.443 \\
KSC-10a & 1.366 & 1.366 & 31.057 & 66.211 \\
KSC-20a & 2.839 & 2.839 & 28.602 & 65.721 \\
\hline
\end{tabular}


Table 3. XPS data for Reade ilmenite (mean of 6 samples)

\begin{tabular}{c|c|c|c|c}
\hline Sample & At $\%-T i$ & At $\%-F e$ & At $\%-C$ & At $\%-O$ \\
\hline Reade ilmenite & 17.07 & 9.57 & 12.54 & 60.83 \\
\hline
\end{tabular}


Table 4. Stoichiometry of minerals

\begin{tabular}{l|l}
\hline \multicolumn{1}{c|}{ Material } & \multicolumn{1}{c}{ Stoichiometry } \\
\hline Reade ilmenite (from Table 2) & $\mathrm{FeTi}_{1.8} \mathrm{O}_{6.4}$ \\
\hline Ilmenite & $\mathrm{FeTiO}_{3}$ \\
\hline Pseudorutile & $\mathrm{FeTi}_{1.5} \mathrm{O}_{4.5}$ \\
\hline Rutile & $\mathrm{TiO}_{2}$ \\
\hline Pseudorutile + Rutile & $\mathrm{FeTi}_{2.5} \mathrm{O}_{6.5}$ \\
\hline
\end{tabular}

